\title{
EL GABINETE COMO DIÁLOGO INTERARTÍSTICO. GONZALO MILLÁN COLECCIONISTA, CURADOR Y POSTPRODUCTOR DE VISUALIDAD ESCRITA ${ }^{1}$
}

\author{
The Cabinet as interartistico dialogue: Millán is an art collector, curator \\ and post-producer of written visuality
}

\author{
Rolando Garrido*
}

\begin{abstract}
RESUMEN
Gabinete de papel funciona como extensión o ampliación del ejercicio entre escritura y visualidad iniciado con Claroscuro y bisagra con Autorretrato de memoria. Si las imágenes creadas por Zurbarán y Caravaggio le sirven como pretexto para marcar un punto de inflexión en su creación literaria, su gabinete como espacio programático le permite ahondar y diversificar su trazo literario, profundizando en modelos artísticos que se aproximan a su poética, de tal manera es reconocible en el grabado de Brueghel o en el óleo de Hopper, como en otros, su ética escritural. Millán es coleccionista y curador que postproduce visualidad escrita.
\end{abstract}

Palabras clave: Gabinete, curatoría, postproducción.

\footnotetext{
${ }^{1}$ Este artículo es patrocinado por el Proyecto Prometeo-SENESCYT República de Ecuador-Universidad de Cuenca (2014-2015) y se inscribe en el desarrollo del proyecto de investigación sobre escritura y visualidad en Ecuador y Chile, titulado "Poéticas de la mirada y escrituras errantes en la construcción de ciudadanía" (1973-2013). Lo concerniente al estudio de la obra de Gonzalo Millán, incluido en el corpus de esta investigación Prometeo recoge aspectos del análisis de Croquis presente en la tesis doctoral realizada en la Pontificia Universidad Católica de Valparaíso.

* Facultad de Filosofía y Educación, Instituto de Literatura y Ciencias del Lenguaje, Pontificia Universidad Católica de Valparaíso. Valparaíso, Chile / Facultad de Filosofía, Letras y Ciencias de la Educación, Dirección de Investigación y Postgrados, Universidad de Cuenca. Cuenca, Ecuador. Correo electrónico: rgarridoquiroz@gmail.com
}

Artículo recibido el 29 de agosto de 2014. Aceptado el 4 de junio de 2015. 


\begin{abstract}
Gabinete de papel works as an extension or expansion of the relation between writing and the visual started with Claroscuro and continued with Autorretrato de memoria. If the images created by Zurbaran and Caravaggio are a pretext for the poet to mark a turning point in his literary output, his cabinet as a programmatic space allows him to deepen and diversify his literary trace, rooting his quest in artistic models that are closer to his poetics. It is possible, then, to recognize, among others, Brueghel's prints o Hopper's canvasses in Millán's ethics of writing. Millán is an art collector and a curator that post-produces a written visuality.
\end{abstract}

Keywords: Cabinet, art curation, post-production.

El gabinete de Gonzalo Millán alude a la materialidad y soporte de un aparato o espacio de papel que pone en diálogo fecundo escritura y artes visuales. Lo material e inmaterial del gabinete de papel $^{2}$ de Millán guarda/desarchiva imágenes que pueblan su memoria y acervo cultural constituido por pinturas, grabados, fotografías, láminas e ilustraciones de todo tipo. Aquí, la materialidad de las imágenes exhibidas está hecha de palabras que varían en superficie, espesor y núcleo, ejerciendo así la capacidad de producir efectos visuales en cada poema. En Gabinete de papel (2008) la escritura puede ser exploración, paneo con la cámara o zoom en un mismo poema, como por ejemplo en "El Alquimista" que cierra este segundo libro de la trilogía Croquis. /Los tres niños revisan un alto armario / como guerrilleros del hambre / el niño mayor calza en la cabeza / una cacerola con tres patas // (Millán, 2008: 80).

Los niños aludidos se encuentran en la parte superior del grabado (real, material) de Brueghel de 1558, lo que hace Millán es focalizar la atención aplicando el efecto zoom, para hacer más evidente el estado de miseria del alquimista y su entorno, mostrándonos de manera concentrada una olla, donde no hay alimento, solo el vano intento de darle otra utilidad (lúdica) al recipiente vacío.

En "El Alquimista" (2008: 80-81) de Millán se hace presente la imagen del fracaso, tanto del oficio como de la vida que circunda al oficiante. La búsqueda de lo que nunca estuvo, de lo que nunca fue, mantiene un mundo de expectativas que sucumben en el intento, uno tras otro, al acumular, no experiencias, sino actos fallidos. En el atiborrado escenario del alquimista, todo se mueve en dirección

\footnotetext{
${ }^{2}$ Pedro Pablo Guerrero en entrevista a Gonzalo Millán el año 2002 en El Mercurio, le pregunta si las restantes obras de la trilogía abarcarían períodos más recientes, a lo cual Millán responde que la segunda parte se iba a llamar Paletas de papel por las paletas desechables. Según el poeta, la muestra era concebida de manera heterogénea, incorporando esculturas, fotografías, obras de vanguardia e instalaciones.
} 
El gabinete como diálogo interartístico.

contraria a su objeto. El alimento que no existe en un lugar guardado, las monedas que nunca estuvieron en el bolsillo del alquimista, el invento que no tiene lógica de prosperar, y al alquimista como director de escena, que se remite a los textos en su escritorio llenos de palabras vacías.

El último poema publicado en Gabinete de papel nos presenta un Millán que, entre otros modelos artísticos, juega con el manierismo, preciso en el detalle, surtiendo de semejanza a su poema con el grabado de Brueghel en el recorrido visual de la escena, al cobrar importancia lo postural del alquimista de mediados del siglo XVI, que aparenta a un baterista del presente en un tipo de estudio o sala de ensayos que, tal vez, nunca vea inscrita la percusión de su música en un disco de oro, nota sustantiva para referirse a la incertidumbre que rodea el mundo del artista, cuya única seguridad es no cejar en el intento que le proporciona el ensayo como práctica sin retribución inmediata.// El flaco alquimista está sentado / como un baterista con sus baquetas / frente a platillos malolientes / y tambores malsonantes // (Millán, 2008: 80).

Gonzalo Millán en este último poema presenta el fracaso de un hacer por su propia inutilidad, mediante la direccionalidad escritural o posición que adopta su escritura al presentar la escena referida al grabado de Brueghel. De tal manera, advertimos que dentro del cuadro de miseria se dan rasgos propios del manierismo como modelo artístico, en el sentido de que la obra queda abierta al poner Millán en la mira, tal cual se evidencia en los versos finales con la fuga de los nińos de ese escenario miserable, que gracias a la ayuda de otros adultos, que entienden su condición y futuro, abren camino en otra dirección. // Mísero" dice la cartela y la ventana / muestra la familia miserable / pidiendo asilo en una embajada de la caridad.//. (Millán 2008: 81).

Con ello, Millán reinstala el sentido de apertura de su propia obra, que no se cierra al cerrar el libro ni tampoco en su primera lectura. Los niños acogidos por la caridad constituyen una salida, un exilio, provocándonos un relato que no se agota en la miseria del alquimista y su intento por hallar la piedra filosofal, así como la obra del poeta no se agota en su capacidad de escribir, sino que nos remite al colectivo en la lectura y su re-lectura.

Gabinete depapel, si bien corresponde al segundo libro en orden programático de la trilogía Croquis, fue el último en escribirse, cuya última versión fue revisada por Millán pocos meses antes de morir, cumpliendo, de una manera u otra, con los compromisos editoriales que el poeta tenía con Ediciones Universidad Diego Portales. En matemáticas puede que el orden de los factores no altere el producto, pero habría que revisar si en la producción millaniana de Croquis, el hecho que Autorretrato de memoria (2005) hubiese sido publicado antes que Gabinete de papel 
(2008) altera o no el sentido programático ${ }^{3}$ de la trilogía. En el año 2002, en una entrevista concedida a Alejandro Zambra sobre la reciente aparición de Claroscuro (2002), Millán argumentaba en relación a la trilogía Croquis por construir:

El libro en realidad tiene tres partes de las que Claroscuro es sólo la primera. En la segunda serie los cuerpos plásticos son muy variados, ya no son pinturas clásicas sino que hay de todo, fotos de diarios, escultura, arquitectura, etc. No sé todavía como se llama. La tercera se llama Autorretrato de memoria y es una suerte de "autobiografía" pictórica pero imaginaria, cuadros que se supone que existen y que están pintados no se sabe por quién, seguramente por aquel que escribe, y entonces él los describe y al describir estos cuadros imaginarios se supone que también describe su vida. En la pintura se supone que es un cuadro en que el autor se autorretrata sin espejo, sin mirarse. Esa es la parte que me falta todavía para terminar el libro, y de la segunda hasta me sobran cosas, el problema es elegir. La tercera es la más complicada porque está relacionada con un proceso terapéutico (Zambra 2002: 5).

Una primera respuesta a este hecho, confirmando el orden programático de Gonzalo Millán respecto de Claroscuro (2002), Gabinete de papel (2008) y Autorretrato de memoria (2005), es que la galería imaginaria de colección de arte y selección de imágenes exhibidas en Gabinete de papel comienza con el epígrafe del historiador y crítico rumano de arte, Víctor I. Stoichiță, quien advierte que la función separadora del marco se repite en la conciencia de la colección como un todo. Stoichiță, en su libro Ver y no ver (2005) plantea que la conciencia, en tanto acto consciente del coleccionista de arte actúa como supermarco ${ }^{4}$.

Stoichiță (2005) rescata el pensamiento que vierte Émile Zola en su libro La pantalla (1866), cuando el novelista francés, al referirse al realismo en el arte de Manet, advierte que cualquier obra es como una ventana abierta a la creación y que existe en el encuadre de la ventana una especie de pantalla transparente, a través de

\footnotetext{
${ }^{3}$ Millán explica en una entrevista con Guerrero, que Autorretrato de memoria es la tercera parte de una trilogía llamada Croquis, que Ediciones Universidad Diego Portales publicaría completa el próximo año y cuya primera parte, Claroscuro, dedicada al barroco, se había editado hace tres años en RIL, mientras que la segunda -inédita a la fecha de la entrevista- se titularía Gabinete de papel con la idea del coleccionismo de imágenes. Millán argumenta que los tres libros en todo caso, son completamente autónomos, aunque dialogan entre sí y establecen comunicaciones subterráneas.

${ }^{4}$ Gabinete de papel comienza con el epígrafe de Víctor I. Stoichiță permitiéndole a Gonzalo Millán advertirnos sobre el tipo de gabinete (su condicionante espacial y su función separadora) que nos va a presentar. Luego, se surte de otro artista rumano, el escultor Constantin Brâncuși para reafirmarnos las características del gabinete millaniano. El epígrafe de Brâncuși lo asimilamos a la reflexión que hace Francisco Leal en su análisis de Claroscuro al referirse al cruce entre el arte y la delincuencia, vistos ambos como lugares que escenifican el exceso y el deseo como vértices de la creación artística.
} 
El gabinete como diálogo interartístico.

la cual se perciben los objetos más o menos deformados, sufriendo cambios más o menos sensibles en sus líneas y su color. Para Stoichiță (2005), las reflexiones de Zola, no se refieren únicamente a la pintura, sino a la representación artística en general. En tal caso, lo más significativo es que, al recurrir a la antigua metáfora del cuadro como "ventana abierta", se convierte en el manifiesto fundamental de la pintura moderna. Cabe recordar que el poema que abre Gabinete de papel es "Ventana". // Una ventana que se abre para recibir / la luz y dejar fuera la tormenta. / Una ventana que regale un paisaje / Escogido por la aurora o el ocaso. // (Millán, 2008: 13).

En tal sentido, Gabinete de papel funciona en Croquis como la posta natural, incluyente, luego de Claroscuro antes de que el poeta -programáticamente- se enmarque en su propio autorretrato como gesto último en la relación que establece entre poesía y artes visuales. Gabinete de papel actúa como extensión o ampliación del ejercicio intersticial entre escritura y visualidad iniciado con Claroscuro. Si las imágenes creadas por Zurbarán y Caravaggio le sirven como pretexto para marcar un punto de inflexión en su creación literaria, situado en el entre paréntesis escritural luego de Virus (1987), obra que marca el cierre de un ciclo y la apertura de uno nuevo, incluyendo la Antología Trece lunas (1997) como signo vital, su gabinete, como espacio programático, le permite ahondar y diversificar su trazo artístico, profundizando en modelos más allá del barroco en el contexto de las artes visuales.

El grabado manierista de Brueghel, El Alquimista, funciona como mecanismo de apertura y vínculo al libro escrito temporalmente en segundo lugar para completar la trilogía, poniendo a prueba, en la visualización del programador, su capacidad de hacer emerger su propio ouróboros ${ }^{5}$ generativo en Autorretrato de memoria.

Los poemas del gabinete de Millán están abiertos al juego inter-artístico, ya que estas piezas no son mera descripción de grabados ni pinturas, sino que en su arquitectura producen efectos visuales de semejanza, de correlato, que se pueden leer como tales sin necesariamente conocer o revisar el modelo, ya sea del grabado de Brueghel, la obra de Boucher, una pintura serial de Van Hoogstraten o el óleo de Hopper.

En los procedimientos de construcción de imágenes de Millán, hay un ejercicio de arquitectura e ingeniería en que el poeta con o sin modelo juega sobre la imagen, creando o dando vida a su propio simulacro artístico, donde el poema como artefacto clonado (o no) de la cultura, lo cotidiano o del arte, inscribe su

\footnotetext{
${ }^{5}$ Figura mitológica referida a un dragón que se devora a sí mismo para volver a nacer. Dragón que se muerde la cola aparece inserto en la antología Trece Lunas (1997) y en la antología Vida (1984) como Ouróboros e Historietas. El ouróboros representa la renovación de los ciclos de la vida.
} 
propio ADN y código de barra a su producto, teniendo por finalidad la creación de un otro a partir de un ello (real, imaginado, experiencial, archivado, desarchivado), cuya función es la de producir diálogo interartístico, del cual resulta determinante la forma que adquiere posturalmente su escritura.

Así entonces, la idea de ventana que propone Stoichiță (2005) hace funcionar al poema como una pantalla generadora de efectos visuales, por una parte, un medio por el cual miramos (leemos), pero que, al mismo tiempo, se erige como simulacro de un primer objetivo observado que cobra vida propia en su capacidad de diálogo entre creación y creación o entre creación y postproducción, ambas con objetos vivientes, donde la mirada se libera de primeras intenciones. Asimismo, Gonzalo Millán concebía los emblemas con una funcionalidad similar. Un emblema -al decir del poeta de Croquis- está constituido por dos partes fundamentales, el cuerpo y el alma; de tal modo, el cuerpo es la imagen y el alma es el poema. De esta manera, Millán sostiene que muchos poemas funcionan como un emblema en que el cuerpo es evocado pero no está (Zambra, 2002).

La propuesta de leer Gabinete de papel como un libro, que no tan solo enlaza coherentemente Claroscuro con Autorretrato de memoria (2005), sino que también cumple la función libresca de plasmar las prácticas escriturales y plásticas del Archivo Zonaglo al interior del Gabinete ${ }^{6}$, permite atender al poema, cuyo proceso de colección y selección artística, activa un viaje por el arte y la cultura para que el lector/espectador se pueda detener, regresar, adelantar indistintamente y en las más diversas trayectorias, entrenando las capacidades de aprender a mirar lo pasado por alto en la perspectiva de ir más allá de un orden espacial y temporal.

En Gabinete de papel se cuelgan obras, imágenes y pensamientos de diversos autores, entre ellos: Víctor Stoichiță, Constantin Brâncuşi, Françoise Boucher, Edward Hopper, Tiziano, Van Gogh, Lihn, Da Vinci, Muhya, Maurice Denis, Frank O’Hara, Michael Goldberg, Samuel Van Hoogstraten, Antonius Wierix, Giorgio Morandi, Carpaccio, Mallarmé, Gon Buurman, Man Ray, Botero, Courbet, Modigliani, Matisse, Velásquez, Francis Bacon, Harmen Steenwyck, Eliseo Diego, Georges Bataille, John Tenniel, José Sánchez Cotán, Escher, Piero Di Cosimo, Lorenzo Di Chimenti, Vasari, Degas, Brueghel y el propio Gonzalo Millán como letrista, compositor, encargado de los efectos especiales y la escenografía de su gabinete de papel.

El coleccionismo en Gonzalo Millán viene como práctica temprana. En este gabinete, su curador es un coleccionista que actúa por selección a partir de la

\footnotetext{
${ }^{6}$ María Inés Zaldívar, en más de una oportunidad, ha insistido en que las fichas del Archivo Zonaglo admiten su lectura como poemas y, al mismo tiempo, también concibe que Gabinete de papel constituye el mismo ejercicio de Millán sobre el Archivo, pero recurriendo a la estructura clásica que ofrece el poema.
} 
identificación de rasgos propios o cercanos a sus prácticas escriturales. La ubicuidad escritural que practica Millán es una constante en su obra, acentuándose dicho ejercicio en Croquis, ya que en el procedimiento que instala el poeta para hacer posible la mirada, nos remite a ciertos puntos o zonas de acceso visual donde se mira "a través de", buscando otras o diferentes perspectivas en su tematización sobre el amor, lo cotidiano, la ciudad, la palabra poética, la pintura barroca o el álbum autobiográfico.

El objeto en la mira, sean cuadros, fotografías o recuerdos, funcionan como pretextos para poetizar al mundo. En tal sentido, el mundo del arte y diversos movimientos y/o modelos encuentran su ajuste en este ojo que escribe una poesía desafiante, crítica, subversiva en su poética, estética y ética, e instala al mismo tiempo, nuevas prácticas de lecturas, atentas, cultas, situadas en el detalle y lo pasado por alto en una sociedad donde todo es de fácil consumo.

El manierismo en Brueghel pone en diálogo a su alquimista con el arte Barroco, una reacción anticlásica que cuestionaba la validez del ideal de belleza definido en el Alto Renacimiento, distorsionando la forma a partir de lo postural, sustentada en la personalidad o manera de quién pinta, experimentando el placer de la transgresión y abriéndose a la posibilidad de la obra inconclusa o abierta. En "El alquimista" de Millán se refleja esta ética escritural en el poema.

De igual manera, las imágenes del "Noctámbulos" de Gonzalo Millán (2008) en relación interartística con el cuadro de Edward Hopper nos permite revisar las claves poéticas de ambos artistas que, en la distancia de sus creaciones ${ }^{7}$, vinculan en cuadro y poema. Al mismo tiempo, es necesario volver a seńalar que para que exista diálogo, Millán tiene que generar su propia versión o el reverso de su imagen otra, dotando de vida y movimiento a la imagen escrita en tiempo y espacio. En tal sentido, el óleo de Hopper se configura en la espacialidad que permite el cuadro y -el poema de Millán- captura de esa presencia doce imágenes posibles de acceso dialógico a partir del juego diversificado de la mirada. El mismo procedimiento escritural que utiliza el poeta como recurso para dar cuenta de la "Santa Águeda" presente en el óleo de Zurbarán presente en Claroscuro.

Gonzalo Millán selecciona para su Gabinete de papel (2008) a Edward Hopper y su óleo Nighthawks. Si en Claroscuro, Millán hace un rescate de una técnica artística y para evidenciar este proceso creativo elige ciertas pinturas de Zurbarán y Caravaggio con los cuales también comparte el oficio del detalle, el juego de los contrastes y

\footnotetext{
${ }^{7}$ La pintura Nighthawks de Edward Hopper (Instituto de Arte de Chicago) fue realizada en 1942. El antecedente motivacional fue el ataque aéreo por parte de Japón a la base estadounidense de Pearl Harbor. La última revisión que hizo Gonzalo Millán de su Gabinete de papel, incluyendo "Noctámbulos", tercer poema del libro fue el mismo año de su muerte, y que luego sería publicado el año 2008.
} 
de la sombra, en el caso de Hopper, empatiza desde su ética o práctica escritural, el sentido privilegiado de la observación, el gusto por imágenes nítidas y limpias, organizada en una composición espacial concentrada, condensada, juego deliberado entre luces y sombras. A Hopper le interesan temas o motivos relacionados con la vida cotidiana estadounidense, particularmente imágenes urbanas, en el caso del poeta de Gabinete de papel, la vida cotidiana y los espacios micropolíticos se insertan como una constante en su poesía escrita y visual. Del mismo modo, Hopper y Millán se involucran con el silencio y lo objetual plasmado en sus trazos, orquestando en sus imágenes sentido de realidad en clave metapoética, cuyo procedimiento artístico se juega en focos atencionales que captan luces frías, cortantes, artificiales de forma similar como opera la escritura de Millán.

\section{Gonzalo Millán curador de su gabinete personal}

La curaduría o curatoría está vinculada al entramado discursivo del campo artístico como ejercicio de poder respecto de su particular lenguaje. Desde esta perspectiva, la hegemonía del arte o la estética, facilita la configuración de mapas globales a partir de sus experiencias particulares; y sus generalizaciones tienden a ser reproducidas en el ámbito institucional de la galería, el museo, la academia o el mercado del arte. En el caso de este estudio, el autor de Gabinete de papel desde su nutrida colección artística y poética selecciona obras y pensamientos que aluden a la naturaleza del lenguaje artístico y a las relaciones existentes entre palabra e imagen. Así, en su galería imaginaria encontramos a artistas de distintas épocas que se vinculan desde los más diversos ángulos con la poética de Gonzalo Millán. Desde este punto de vista, ninguno de los artistas, pintores, poetas o pensadores evocados resulta ajeno a los procedimientos escriturales que cultivó Millán en su trayectoria como escritor.

El diálogo interartístico que emprende el poeta con cada uno de los autores citados dan cuenta, no solo de preferencias y/o aproximaciones a poéticas, estéticas y éticas que configuran un arte determinado, sino, cómo ciertos modelos artísticos funcionan a la manera de marcos explicativos al servicio de lecturas que indefectiblemente surgen desde una poesía de la mirada. En ello, el curador de su propia galería proyecta, amplía los cuartos de su galería imaginaria, invitando a un viaje con un menú de trayectorias posibles que, en su proceso programático, concibe el retorno a sí mismo, como un retorno al lugar de todos.

Continuando con la idea del curador, Jane Q. Kessler $(1995)^{8}$ establece criterios para evaluar una exhibición. En su artículo describe los catorce puntos

\footnotetext{
${ }^{8}$ Kessler publicó un artículo en Fiberarts Magazine referido a las funciones o rol del curador planteando catorce puntos. Solo abordaremos los puntos más relevantes desde la perspectiva del análisis de Gabinete de papel y de la figura de su autor como curador de su galería imaginaria.
} 
El gabinete como diálogo interartístico.

para el papel del curador. Al respecto analizaremos solo algunos de estos puntos, a la luz de la figura del curador-poeta invitándonos a visitar/recorrer una galería imaginaria en Gabinete de papel.

Uno de los criterios, el tercer punto que establece Kessler (1995), indica que hacer la curaduría de una exhibición, es cuidar de ella como si se estuviera escribiendo un cuento o un poema. El proceso es subjetivo y objetivo a la vez. Se usan cosas y se combinan esas cosas de manera que se pueda describir o iluminar algún aspecto de la actividad o de la creatividad humana.

En Gabinete de papel, la selección por cierto que es subjetiva, responde a la especial y singular relación del artista Millán con el arte en sentido amplio y genérico. En el gabinete del poeta se evocan realizaciones plásticas que nos remiten a combinaciones de elementos, describiendo atmósferas, pero, por cierto, también técnicas que pintan o graban de manera más lúcida ciertas atmósferas, ya sea el poema serial "Noctámbulos/Edward Hopper" (Millán 2008: 15-19) como pretexto para describir doce escenas a partir de una sola imagen o dando vuelta la mirada y los roles en un blues de Nina Simone como se aprecia en Don't smoke in bed (2008: 20).

El quinto criterio de Kessler (1995), hace referencia a que hay exhibiciones e ideas de curaduría que están bien fundamentadas y apoyadas por procesos de selección, presentación y material didáctico. En tal caso, los epígrafes y referencias a títulos de obras de arte que inscribe Millán antes de la lectura de sus poemas evidencian las cargas intertextuales que fundamentan y apoyan el proceso de selección al permitirnos indagar en el pensamiento y obra de autores que contextualizan de manera didáctica el artefacto aludido (pintura, grabado, fotografía, blues) con el poema presentado, así Van Gogh y Lihn son los teloneros del recital de Millán re-interpretando la obra de Hopper. El mismo sentido pedagógico y/o didáctico ocurre con el estante de cartas de Samuel Van Hoogstraten, donde el curador nos obliga a ir revisando las diferentes versiones pintadas de la composición de Trompe l'oeil. De tal manera, nos vemos participando de un catálogo y un índice nutrido de la historia del arte.

El sexto criterio de Kessler (1995) indica que el proceso de la curaduría comienza con una tesis. La tesis, sin embargo, se deriva de un propósito. El problema está en que hay que saber diferenciar entre "propósito" y "tesis", de manera que ambos se lleguen a comprender plenamente en una exhibición. Un curador plantea un enunciado, una declaración, una tesis, una idea a la que se le dará un seguimiento tangible a través de la selección y exhibición de objetos o, en algunos casos, de no-objetos.

La tesis principal que nos plantea Millán es sobre el mismo concepto de gabinete y de la idea que concibe de arte. Las marcas inscritas con los pensamientos de Stoichiță (2005) sobre el gabinete y de Brâncuși sobre el arte operan como 
los enunciados necesarios que prefiguran la galería expuesta en Gabinete de papel. Por una parte, la función separadora del marco se opone a lo que no está dentro del cuadro, fundamento básico en la tarea del coleccionista y de esta selección en particular encuentra su correlato en la segunda mitad del poema "Ventana" exhibido en este libro, que refrenda la tesis rescatada en el pensamiento de Stoichiță (2005). // Una ventana como un camino / y un caminante que camina / para olvidar su caminar. / Una ventana como el marco de un sueño / Una ventana cerrada, con una cortina. // (Millán 2008: 13).

El marco de la ventana delimita, pone adentro lo que quiere mostrar. Abrir o cerrar la ventana es exhibir este cuadro con escenas. Las cortinas actúan por oposición en el proceso de colección-selección que el poeta quiere mostrar. El camino y su caminante (en) marcan el paisaje, existen dentro del marco por efecto de la luz que ofrenda el amanecer o atardecer. En tal sentido, esta poesía de la mirada muestra lo que quiere mostrar, haciendo consciente aquello que es parte de su juego de exhibición focal. Los artistas que aparecen en la ventana que nos abre Millán configuran el supermarco de su poética, así como la idea de arte de Brâncuși evocan austeridad y drama, en la selección del curador nos vuelve a recordar o advertir sobre qué tipo de poesía estamos en presencia, que es actualizada en la lectura.

Para Kessler, el argumento del séptimo criterio, radica en el buen trabajo de curaduría se hace evidente a través de un sólido proceso de pensamiento que sirve para presentar una opinión específica de manera que pueda estimular tanto al propio curador, como a sus colegas y al público en general. El próximo problema estriba en determinar cómo y por qué se seleccionan los objetos y los artistas. Si el propósito de la exhibición consiste en iluminar y expandir la comprensión de un tema en particular, entonces el curador tiene la responsabilidad de ser diligente en el proceso previo de investigación, que como apreciamos en el caso de Gonzalo Millán, asistimos a una laboriosa implicación entre escritura poética y artes visuales en la selección de los artistas que componen la muestra de Gabinete de papel.

En el noveno punto Kessler advierte que el ensayo para un catálogo no debe servir para exhibir las cualidades de un escritor, sino de ser un instrumento creativo que pueda ofrecer una comprensión más rica del tema de la exhibición. Es esto precisamente lo que Millán propone al situar los epígrafes de Stoichiță y Brâncuși como lecturas previas, ya que la captura de estas reflexiones invita a la revisión de dichas ideas para captar la esencia y sentido de un gabinete heterogéneo $\mathrm{y}$ vinculante.

Una de las preguntas principales que nos podemos hacer de la muestra que ofrece Millán es cómo funciona en tanto catálogo. La respuesta tentativa es si remite a un aprendizaje sintético de las múltiples relaciones entre artes visuales y poesía, podríamos aproximarnos a la idea que Gabinete de papel funciona como un catálogo resultante de procesos de colección, selección, producción y postproducción. Los 
El gabinete como diálogo interartístico.

más de treinta artistas citados o convocados en su gabinete de papel sintetizan siglos de arte, llevando cada lectura o una relectura de diversos modelos artísticos y cómo éstos engendran empatía con la propuesta artística poética de Gonzalo Millán a través de sus poemas.

\section{Postproducción, archivo poético y galería imaginario}

Gonzalo Millán no es mediador de su propio gabinete en sentido estricto, ya que no media entre el arte y el observador desde una perspectiva imparcial y neutra, sino todo lo contrario, es parte interesada, sobre en el mismo proceso de selección y exhibición del arte y su combinatoria. Dicho lo anterior, el autor de Gabinete de papel funciona como curador en tanto representa un actor que invita a la generación de un diálogo interartístico a partir de la lectura de su gabinete, al poner en evidencia su capacidad selectiva para postproducir arte.

El concepto de postproducción lo aborda Nicolás Bourriaud (2004) para referirse a la idea de "la cultura en uso" en el mundo del arte y la figura del artista como semionauta, en el marco de la edición de su libro Postproducción (2004) en Buenos Aires ${ }^{9}$. En esta nota, el crítico de arte y curador francés señala:

La mundialización de las artes y las letras, la proliferación de productos culturales y la disponibilidad de saberes en internet, por no hablar de la erosión de los valores y las jerarquías nacidos en el modernismo, crean las condiciones objetivas de una situación inédita que los artistas exploran en obras que dan cuenta de esto a la manera de un itinerario u "hoja de ruta". Internet sugiere el método de la navegación razonada, intuitiva o aleatoria y ofrece una metáfora absoluta del estado de la cultura mundial: una cinta líquida en cuya superficie se trata de aprender a pilotear el pensamiento. La capacidad de navegar por el saber está a un paso de convertirse en una facultad predominante para el intelectual o el artista. Releyendo los signos entre sí, produciendo itinerarios en el espacio sociocultural o en la historia del arte, el artista del siglo veintiuno es un semionauta (Bourriaud 2004: 1).

Para Bourriaud (2004) la hoja de ruta podría ser el emblema de una segunda modernidad que sucedería a esa fase de transición que fue el posmodernismo, reagrupando a navegantes de la cultura que toman como universo de referencia las formas o la producción imaginaria. La producción de formas mediante la recolección de información, evidencia como método, una preocupación central al afirmar el arte como una actividad que permite dirigirse, orientarse, en un mundo cada vez más saturado de información y disponible en formato digital, cuestión que se puede apreciar en la producción millaniana del Archivo Zonaglo (1986-2006), en

\footnotetext{
${ }^{9}$ La nota apareció publicada en Página 12 el día martes 6 de abril del 2004.
} 
particular, sobre el uso de las fichas que adopta el artista visual de Gonzalo Aguirre en su video arte El Archivo Zonaglo ${ }^{10}$ (2008). Asimismo, el coleccionismo de arte practicado por Millán, a través del uso de las obras del pasado y de la producción cultural de dichas obras, considerando el proceso de selección compatible con la poética que propone su poesía escrita, resulta como un esquema orientador de los poemas que exhibe o expone Gabinete de papel, dialogando con el arte universal, y especialmente con ciertos artistas, que anteriormente navegaron espacialmente por los signos de la cultura.

El autor de Postproducción intenta sentar las bases para una cultura del uso de las formas, de los signos y de las obras. Este gesto artístico es reconocible en el gabinete de Millán, ya que al decir del crítico y curador francés:

$\mathrm{Al}$ volverse generador de comportamientos y de nuevos usos potenciales, el arte viene a contradecir la cultura 'pasiva' oponiendo las mercancías y sus consumidores; hace funcionar las formas dentro de las que se desarrollan nuestra existencia cotidiana y los objetos culturales propuestos para nuestra apreciación. ¿Y si la creación artística pudiera hoy compararse a un deporte colectivo, lejos de la mitología clásica del esfuerzo solitario? (Bourriaud 2004: 1).

La poesía y arte plástico producido por Gonzalo Millán luego de Virus (1987) y su silencio hasta Claroscuro (2002), profundizan las prácticas escriturales de Millán en tanto el arte es concebido como componente de una cultura del uso, expresado en su coleccionismo y procesos de selección, producción y postproducción. De este modo, torna dialógico el material que se edita. Al respecto, Bourriaud se pregunta ¿Por qué el sentido de una obra no podría provenir tanto del uso que se hace de ella como del sentido que le da el artista? En tal sentido, el blues que canta Nina Simone "Don't Smoke in Bed" (2008: 20) le permite a Millán variar su mirada de la escena ${ }^{11}$ para configurar el reverso de la imagen poetizada de la misma forma en que el poema de Millán "Quodlibet" (2008: 30) sobre el cuadro de Samuel Van Hoogstraten, pone en juego al lector ${ }^{12}$ con su sentido de

\footnotetext{
${ }^{10}$ Aguirre, con la autorización de Gonzalo Millán, digitaliza alrededor de 7.000 de las 15.000 fichas que configuran su obra de poesía visual plástica Archivo Zonaglo. Un primer trabajo audiovisual sobre la animación digital de las fichas fue La Fuente de Mimir (2006) y posteriormente El Archivo Zonaglo (2008). Anteriormente, Millán había autorizado la publicación artesanal de sus fichas en la publicación del Archivo Zonaglo editada por Animita Cartonera el ańo 2005.

${ }^{11}$ El blues/poema de Millán es cantado por quien se queda en la cama y no por quien se marcha de la habitación como sucede en la pieza musical original.

${ }^{12}$ Gabinete de papel admite una lectura navegante por parte del lector, ya que este gabinete invita a indagar el arte como dato situado, bien por internet o escudrińando en enciclopedias o libros de arte sobre el diálogo poema/cuadro/imagen visual que provoca Gonzalo Millán con la presentación de sus poemas.
} 
búsqueda relativo a cuál de las versiones del cuadro pintado por Van Hoogstraten se aproxima a la postproducción que habilita Millán en su poema como acto de abolición de la propiedad de las formas.

Gonzalo Millán postproductor de Gabinete de papel, desde la perspectiva de este análisis, se puede situar en la figura del artista como semionauta que nos anuncia Bourriaud (2004). Un practicante para quien la obra pegada a su firma no constituye otra cosa que un punto dentro de una larga línea sinuosa de tráficos, bricolajes. De esta forma, se podría denominar artística toda actividad de formación y de transformación de la cultura, particularmente en el caso de artistas y poetas descentrados. Millán, producto de su situación de exilio, desexilio e insilio logra asimilar el sistema central del arte contemporáneo, cuestión manifiesta de manera temprana en su poesía, al igual que otros poetas de la promoción emergente que sufre la diáspora forzosa después del Golpe de Estado de 1973 en Chile.

Por otra parte, y en referencia a la idea de postproducción que postula Bourriaud (2004), advierte que lo que podría llamarse interculturalismo se basa en un doble diálogo: aquel que el artista mantiene con su tradición, y al que se agrega un diálogo entre esta tradición, y el conjunto de valores estéticos heredados del arte moderno que fundan el debate artístico internacional. De igual modo plantea que, los artistas interculturales fraguan sus vocabularios en la matriz modernista y releen la historia de las vanguardias a la luz de sus respectivos entornos visuales e intelectuales específicos.

La errancia geográfica de Millán también se expresa en los procesos de edición, re-edición y postproducción de su obra. De la antología Vida, selecciona los poemas "Paleta" (44), "Naturaleza muerta con cama" (45), "Pintor y modelo" (46), y "Ananás y anémonas" (47) para alojarlos o resituarlos en Gabinete de papel. Lo mismo efectúa con un trabajo de investigación sobre el color azul, que se puede evidenciar en "Estudios Ultramarinos" (22) encabezado por un epígrafe de Leonardo da Vinci. Lo interartístico en Millán se puede apreciar en su forma de poetizar el arte barroco de Caravaggio y Zurbarán expuestos en Claroscuro, así como en la selecta muestra que exhibe su gabinete.

El productor y postproductor de Gabinete de papel es un artista avezado y culto en el arte de la programación que nos ofrece Croquis como proyecto poético. El último libro revisado en vida por Gonzalo Millán, con el diario de vida y muerte Veneno de Escorpión Azul (2007) de por medio, juega a favor del archivo y galería imaginaria que por años supo cultivar el poeta, consistente con su poética de la mirada y dialógico curador de su propia colección de arte. En el caso de Millán, el proceso de construcción de la imagen poética posibilita un arte que se expone dentro del marco de su ética escritural. 


\section{REFERENCIAS}

Bourriaud, Nicolás. Postproducción. Buenos Aires: Editorial Adriana Hidalgo, 2004.

Bourriaud, Nicolás. "Los artistas son semionautas". Página 12. Plástica. Martes 6 de abril de (2004): 1-3.

Guerrero, Pedro Pablo. "Una mudez laboriosa” (entrevista a Gonzalo Millán). Revista de libros, El Mercurio (sábado 27 de julio de 2002): 15-18.

Guerrero, Pedro Pablo. "Recordar es despertar" (entrevista a Gonzalo Millán). El Mercurio. Disponible en: http://www.letras.s5.com/gm040705.htm [Consultado el 20 de julio de 2009].

Kessler, Jane. "El papel del curador". Fiberarts Magazine. Volumen 20. Enero/febrero. 4 (1995): 26-27.

Leal, Francisco. "Claroscuro de Gonzalo Millán" (Primera lectura). Disponible en: <http:// www.letras.s5.com/gm270406.htm>. [Consultado el 13 de octubre de 2010].

Millán, Gonzalo. Gabinete de papel. Santiago de Chile: Ediciones Universidad Diego Portales, 2008.

Millán, Gonzalo. Autorretrato de memoria. Santiago de Chile: Ediciones Universidad Diego Portales, 2005.

Millán, Gonzalo. Claroscuro. Santiago de Chile: RIL Editores, 2002.

Millán, Gonzalo. Strange Houses. Canadá: Split Quotation, 1991.

Millán, Gonzalo. Virus. Santiago de Chile: Ediciones Ganímedes, 1987.

Millán, Gonzalo. Vida. Canadá: Ediciones Cordillera, 1984a.

Millán, Gonzalo. Seudónimos de la muerte. Santiago de Chile: Ediciones Manieristas, $1984 b$.

Millán, Gonzalo. La ciudad. Canadá: Les Editions Maison Culturelle QuébecAmérique Latine, 1979. 
Millán, Gonzalo. Relación personal. Santiago de Chile: Arancibia Hermanos, 1968.

Stoichiță, Víctor. Ver y no ver. España: Ediciones Siruela S.A., 2005.

Stoichiță, Víctor. Simulacros: El efecto Pigmalión. De Ovidio a Hitchcok. España: Siruela S.A., 2006.

Zambra, Alejandro. Soy absolutamente anti música. Conversando con Gonzalo Millán. 2002. 